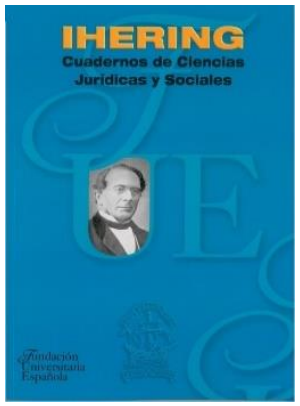

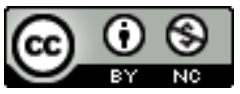

Ihering. Cuadernos de Ciencias Jurídicas y Sociales N. 04

Año: 2021

Publicación del SEMINARIO DE ESTUDIOS EUROPEOS "DIEGO DE MENDOZA" de la

Fundación Universitaria Española

e-ISSN: 2660-552X

DOI: https://doi.org/10.51743/ihering.205

Recibido: 10-03-2021 | Revisado: 24-03-2021

|Aceptado: 05-04-2021 | Publicado: 23-12-2021

\title{
EL CRISTIANISMO EN EL MUNDO SÍNICO: EVOLUCIÓN DE LAS RELACIONES CRISTIANAS CON CHINA
}

\author{
CHRISTIANITY IN THE SINIC WORLD: EVOLUTION OF CHRISTIAN RELATIONS WITH \\ CHINA \\ Borja García Vázquez \\ Orcid: http://orcid.org/0000-0003-0055-6917 \\ Universidad Autónoma de Nuevo León (México)
}

\section{Resumen}

El cristianismo es la religión mayoritaria del mundo. Su impronta ha sido esencial para la creación de occidente, en donde guarda sus profundas raíces, gozando sin embargo de un carácter universal. Dentro de esta expansión, República Popular China es testigo de su notable avance, llevando a algunos especialistas a considerar que para 2050 podría ser el país con mayor población cristiana. Atendiendo a esta realidad, se presenta el desarrollo del cristianismo en el lejano Oriente, a fin de 
explicar cuál ha sido y es, la relación entre esta religión con los habitantes y gobernantes del país asiático.

Palabras clave: cristianismo; China; misiones; evangelización; libertad religiosa; persecución contra cristianos; protestantismo.

\section{Abstract}

Christianity is the predominance religion in the world. Its imprint has been essential for the creation of the West, in which it keeps its deep roots, and yet it has enjoyed a universal character. Within this expansion, the People's Republic of China is witnessing its remarkable progress, leading some specialists to consider that by 2050 it could be the country with the largest Christian population. Taking into account this reality, the development of Christianity in the Far East is presented, in order to explain what has been and is, the relationship between this religion and the inhabitants and rulers of this Asian country.

Keywords: Christianity; China; missions; evangelism; religious freedom; persecution against Christians; protestantism.

\section{INTRODUCCIÓN}

Las palabras del Papa Juan Pablo II en su visita a Santiago de Compostela, con motivo del año santo Jacobeo, el 9 de noviembre de 1982, describen el innegable origen cristiano en la fundación de Europa, tal como reprodujo Suárez Verdeguer (1983):

La historia de las naciones europeas va a la par con su evangelización; hasta el punto de que las fronteras europeas coinciden con las de la penetración del Evangelio" (y lo que es más) "se debe afirmar que la identidad europea es incomprensible sin el cristianismo, y que precisamente en él se hallan aquellas raíces comunes de las que ha madurado la civilización del continente, su cultura, su dinamismo, su actividad, su capacidad de expansión 
constructiva también en los demás continentes; en una palabra, todo lo que constituye su gloria (876).

En síntesis, una exposición de los invaluables aportes ofrecidos por el cristianismo a Europa, pueden obtenerse de la identificación efectuada por Negro Pavón (2003: 689-734): la familia, fundada en el amor; la difusión de la metafísica y la política procedente de la Antigua Grecia, anejo a cambios en la percepción de la razón, la justica, la libertad de acción y pensamiento (como elementos cimentadores de la igualdad entre las personas, y la dignidad humana), y su difusión a todos los estratos sociales; la noción de creación, fomentando la inteligencia en el pensamiento europeo hasta concebir al individuo como figura que trata de evocar a su creador, reconociéndose el mérito al trabajo y el avance de la técnica, por desacralización de la naturaleza; la democracia, como sublimación de la nueva percepción de libertad e igualdad, negando los privilegios de un grupo social sobre los demás; el Estado, a través de la idea de soberanía proveniente de la Iglesia; la ciencia, por inclusión de la providencia, el entendimiento de la existencia de una ley eterna y la capacidad por ende, de crear un determinismo metodológico con que ser capaz de conocer la naturaleza; la historia, al distinguir cualitativamente el pasado, presente y futuro de la realidad humana, y en ella misma la idea de progreso, mediante la teología de la historia; y el laicismo, al diferenciar lo material, temporal, y profano del César, frente a lo espiritual, sagrado, y atemporal de Dios.

Europa junto con Norteamérica y América Latina, conforman los espacios geográficos en los que se asienta la civilización occidental (Huntington, 2019: 51), siendo un elemento común a todos ellos, la presencia del cristianismo. Sin embargo esta situación podría cambiar en las próximas décadas, ya que algunos de los países de esta civilización, podrían dejar de profesar el cristianismo como religión mayoritaria entre sus poblaciones, debido a cambios demográficos y culturales. 


\section{Gráfico 1.}

Porcentaje en estimación de países occidentales que dejarán de tener población mayoritariamente cristiana para el año 2050.

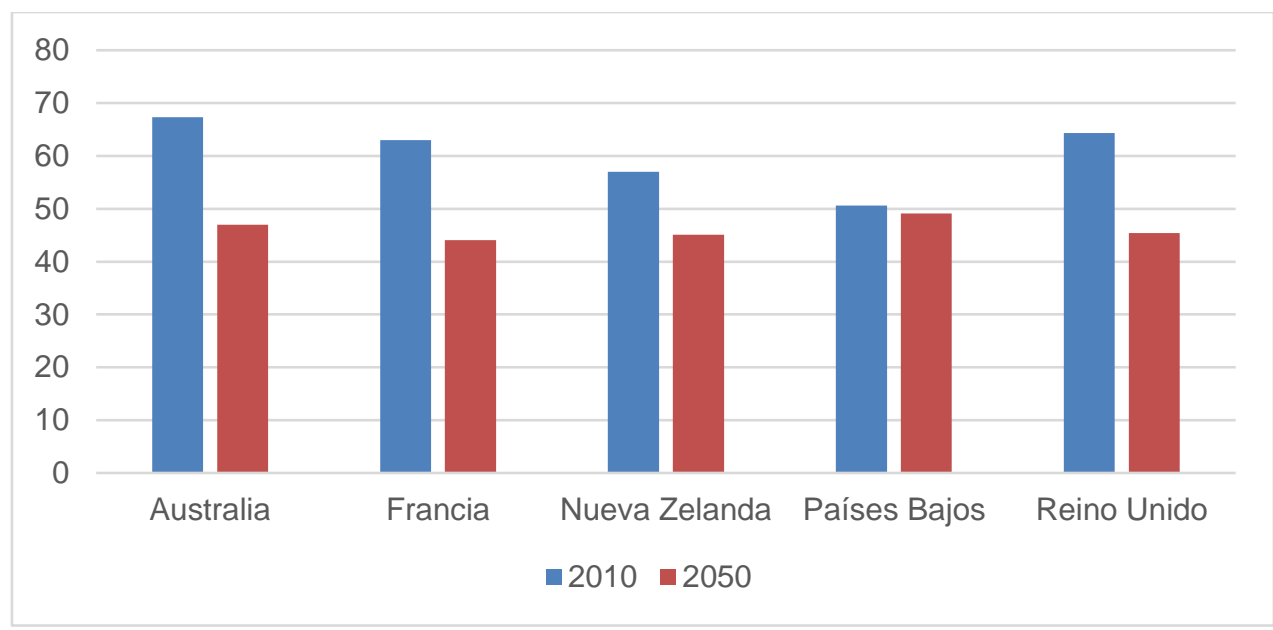

Fuente: elaboración propia, a partir de información de Pew Research Center (2015: 18).

Actualmente Europa mantiene las denominaciones cristianas como religión principal (con el $74.5 \%$ de su población declarándose adscrita a dichos cultos), previéndose que se mantenga en igual situación para 2050 (aunque decreciendo hasta el 65.2 \% en la población creyente) (Pew Research Center, 2015: 147), esperándose idéntica evolución para Norteamérica, del $77.4 \%$ actual, al $65.8 \%$ en 2050, y en América Latina para el mismo periodo, del $90 \%$ al $88.9 \%$, respectivamente (Pew Research Center, 2015: 158). Esto resulta destacable si esta proyección se compara a lo esperado en la región de Asia-Pacífico, en la que se concentra el mayor número de personas aconfesionales. 


\section{Gráfico 2}

Relación estimada de la evolución de población cristiana y sin afiliación religiosa para el año 2050

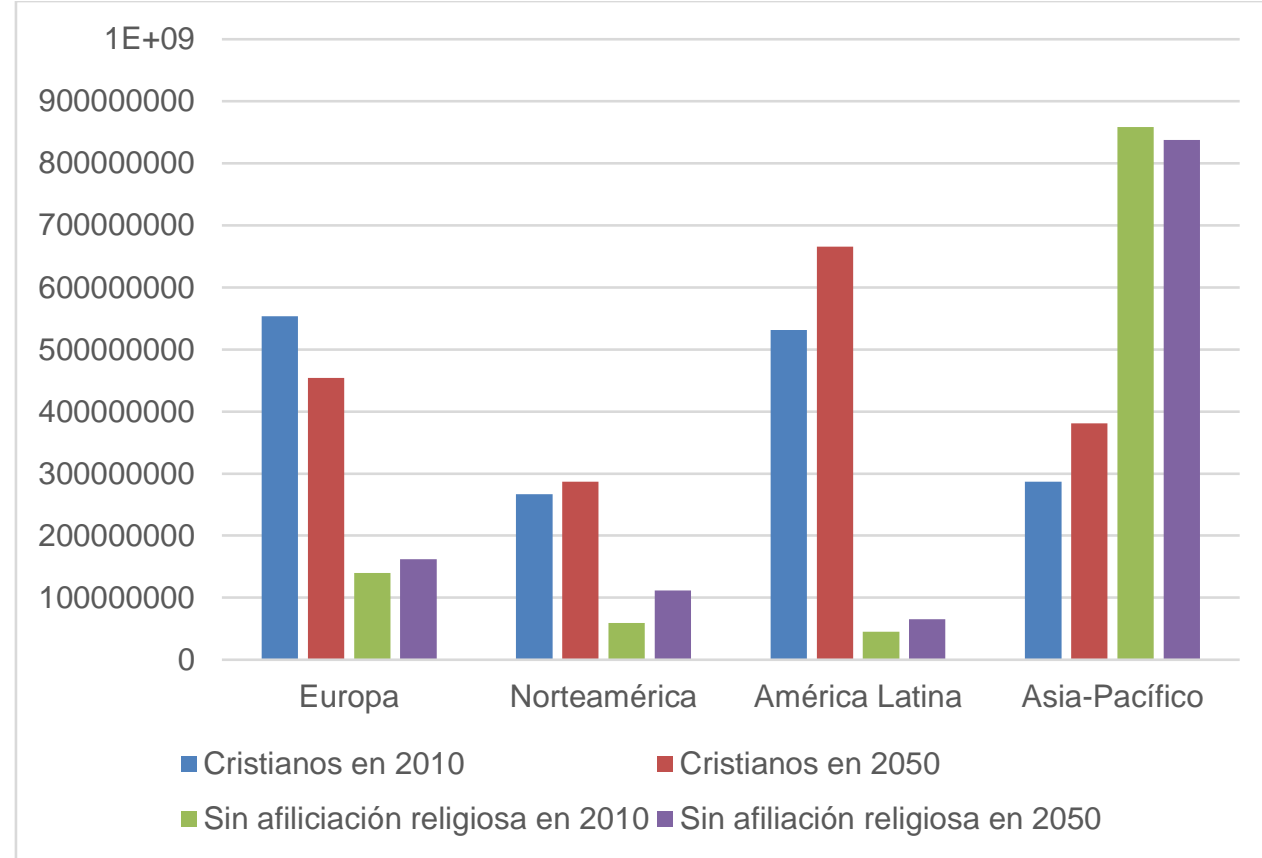

Fuente: elaboración propia, a partir de información de Pew Research Center (2015: 62 y 82). Se advierte que las cifras responden a millones de personas por área geográfica.

Históricamente las religiones han sido atacadas por creerlas un impedimento a la realización de las personas, o ensalzadas al percibir en ellas un poderoso vivificador. Esta dicotomía ha sido sincretizada en palabras de Verstrynge (2012) al entender que "han sido opio del pueblo o, a la inversa, elemento fundamental para la resistencia de personas y pueblos a la opresión" (274), siendo extrapolable a la especial situación vivida en República Popular China, el país con mayor población, caracterizado por un gobierno restrictivo frente a la presencia de religiones en su territorio, que vive el constante incremento en el número de fieles cristianos (sin importar su separación histórica cultural de occidente). 
Atendiendo a esta realidad, el estudio del presente artículo se centra en responder cuál ha sido la evolución, arraigo y relación del cristianismo con China, diferenciando para ello tres espacios de tiempo concatenados: el periodo que abarca desde la fundación de esta religión, hasta la llegada estable de los occidentales al país asiático en el siglo XIV; la etapa de imposiciones extranjeras durante el siglo XIX y la primera mitad del siglo XX; finalizando con los años que transcurren desde la fundación de República Popular China en 1949, hasta la actualidad.

\section{LA EVOLUCIÓN DEL CRISTIANISMO EN CHINA DESDE SUS ORÍGENES, HASTA LA APARICIÓN DEL IMPERIALISMO EXTRANJERO (635 d.C. a 1724)}

China constituye en sí misma una excepción en el panorama internacional, junto con India. Estos países son civilizaciones con miles de años de antigüedad, remontándose en el caso sínico al 1.500 a.d.C., como "civilización china única e inequívoca" (Huntington, 2019: 50).

Si tratamos de fijar los pilares fundacionales de Occidente y Oriente, estos podrían datarse en el Imperio Romano y el Imperio Han, respectivamente. Dos grandes potencias político-militares, que ejercían su poder hegemónico en extensos territorios, sin que llegase a producirse su contacto efectivo por la acción de las potencias territoriales intermedias, especialmente por el Imperio Parto (a través de Persia llegando hasta los márgenes de India), que mantenía el monopolio de las rutas comerciales entre ambos gobiernos, y el Imperio Kushan (que lo hacía a su vez entre Transoxiana y Bactria) (McLaughlin \& Jin Kim, 2021).

Estos actos no impidieron el conocimiento de la existencia recíproca de ambas sociedades por sus gobernantes. Así, las fuentes chinas del siglo I d.C., informaban de la aparición de un gran imperio en el oeste, "Da Qin" (traducido como la Gran China) con el que se aludía al Imperio Romano, entendiéndolo como un 
ente igual y contrapuesto en poder y extensión al propio Imperio Han (McLaughlin, 2010: 21). Asimismo, a través de Plinio el Viejo, han llegado escritos en los que él mencionaba a los "Seres" (traducido como gente de seda), referente a las personas nativas del lugar en que se producía la misma, la cual era uno de los bienes más deseados del Imperio (McLaughlin \& Jin Kim, 2021).

Como resultado de la necesidad de los productos de India y China, se desarrolló una actividad comercial entre occidente y oriente por un valor de 100 millones de sestercios anuales, pagados en oro (Montero, Bravo, \& Martínez-Pinna, 1991: 252), favoreciendo el auge de las provincias levantinas, gracias a las mercancías que transitaban por sus territorios (Le Gall \& Le Glay, 1987: 518).

La gran diferencia entre el sistema occidental y oriental, fue que este último siempre trató de obtener el dominio a través de la psicología, sirviéndose de sus adelantos y comportamiento internacional, sin constituirse nunca como "una sociedad misionera", tratando siempre de "inducir respeto, no fomentar la conversión (...) no buscó exportar su sistema político; más bien hizo que los otros accedieran a él" (Kissinger, 2016: 220-221). Este hecho también se aprecia desde el plano religioso, en tanto que las religiones originarias de China se fundan en la figura del sabio, y las procedentes de Oriente Próximo (cristianismo) se instituyen en profetas, encontrándose la divergencia entre la espiritualidad chino-sapiencial y semítico-profética (Küng, 2013), por lo que al contacto sostenido entre las sociedades occidental y oriental a través de la actividad comercial, debe sumarse la introducción del pensamiento cristiano en el país asiático, como vía de interacción entre ambos mundos.

Jesús de Nazaret, judío de Galilea, figura histórica nacida en tiempos del emperador Augusto en la provincia romana de Judea, cuyo mensaje quedó recogido por obra de los evangelistas y sus seguidores, los cristianos, supuso un punto de inflexión en el pensamiento de Roma, constituyendo un pilar clave en la consolidación de Occidente, y marcando el comienzo de nuestra era. 
Perseguidos en sus orígenes, los cristianos fueron considerados como una amenaza al Imperio al oponerse a los cultos oficiales, siendo tratados como criminales comunes por su sistema jurídico (Mateo Donet, 2016: 7), lo que llevó a un endurecimiento progresivo de las normas, que culminó en el siglo III, con las persecuciones iniciadas por los Emperadores Decio, Valeriano, Diocleciano, y Galerio, quien antes de su muerte en el 311 d.C. decretó la libertad religiosa (González Salinero, 2005: 72), hecho que propició que sus sucesores occidental y oriental, Constantino y Licinio respectivamente, aprobasen el Edicto de Milán en el año 313 d.C. concediendo total libertad a los cristianos (González Salinero, 2005: 73).

El teólogo Nestorio, nacido en Germanicia en el 381 d.C., predicó el reconocimiento de una doble naturaleza y persona dual (divina y humana), en Jesucristo, negando a la Virgen María como Madre de Dios, posición contraria a la mayoría de teólogos del Imperio, lo que provocó su declaración herética en el Concilio de Éfeso en el 431 d.C. (Piñero, 2007: 250-251).

Así surgió el nestorianismo, una iglesia cismática que se expandió por Oriente, formando comunidades en Irán e Iraq en torno al 450 d.C., en India en el 500 d.C., (Piñero, 2007: 254) y en China en el 635 d.C., donde un monje sirio cristiano fundó en la era T'ang, un monasterio con permiso del emperador, aunque sin llegar a tener impacto en la población local (Franke \& Trauzettel, 1982: 176), más allá de la permisividad en el reconocimiento a los cristianos (conocidos como Jinjiao, traducible como los de religión luminosa), hasta su completa prohibición en el 845 d.C. por el Emperador Wuzhong, quien emprendió una campaña conjunta para erradicar el budismo y el cristianismo (Fuk-Tsang, 2011: 150).

En los siglos de crecimiento del nestorianismo, se produjo el colapso y desvanecimiento del Imperio Romano de Occidente, sobreviviendo su parte oriental, conocida como Imperio Bizantino. Tras la desaparición del Imperio Occidental, la Iglesia se constituyó como eje vertebrador (alzándose a su cabeza el obispo de Roma, conocido como Papa), con una influencia terrenal que operará como 
continuadora del romanismo, posibilitando la aparición de comunidades monacales, principalmente bajo las reglas de San Benito, los benedictinos, establecidos en el año 529 (Pirenne, 1993: 102).

Posteriormente surgieron otras órdenes religiosas, como los cartujos en 1084, los cistercienses en 1098, o los franciscanos en 1209, a quienes corresponde el logro en el acceso del cristianismo en China. Fray Juan de Monte Corvino en el siglo XIII, tras ser enviado por el papa Nicolás IV en 1289, consiguió alcanzar Beijing en 1294, donde conoció y presentó personalmente al Emperador Khan una carta de su Santidad, convirtiendo a unas 30.000 personas al cristianismo en el país (Yan, 2014), aunque apenas unas décadas después de su fallecimiento en 1328, el ascenso al poder de la dinastía Ming en 1368 desencadenó un periodo de persecuciones que acabó con cualquier rastro católico hasta el siglo XVI (GarcíaVilloslada, 1940: 347).

La fundación de la Compañía de Jesús el 15 de agosto de 1534, se efectuó en un contexto en el que desde Occidente no se contemplaban formas de cristianismo distintas de la proveniente de Roma, existiendo desconocimiento ante otras denominaciones, como demostró San Francisco Javier, quien a su llegada a la isla de Socotora en 1542, encontró comunidades cristianas del rito sirio, antes ignoradas por Europa (Sotomayor Muro, 1991: 220-221).

El 15 de agosto de 1549, quince años después de la fundación de la Orden, San Francisco Javier llegó al reino de Kagoshima, comenzando una estancia de dos años y medio en Japón, un entorno yermo y hostil al cristianismo, en el cuál a través de la convivencia con sus gentes, aprendió la elevada estima que se tenía entre los japoneses a los conocimientos procedentes de China, una cultura considerada por ellos como superior, lo que decantó el interés de Francisco por evangelizar China, como vía para alcanzar la conversión de Japón (Bangert, 1981: 49-51)

Tras la muerte de Francisco Javier, el Visitador jesuita de la India, Alessandro Valignano, centró su trabajo en la ardua empresa de cristianizar China, disponiendo que sus misioneros aprendiesen el idioma chino para que iniciasen su 
predicación sin que la lengua supusiese más una barrera, y conseguir con ello un cambio en la perspectiva que el mundo sínico tenía de los extranjeros (Marino, 2017: 401), quienes percibían a cualquier occidental como un "merodeador ávido sólo de conquista" (Bangert, 1981: 198), existiendo desconfianza hacia los jesuitas por los funcionarios imperiales, que intentaban no tener contacto con los foráneos por miedo a perder sus empleos (Marino, 2017: 409).

Desde la Corte Imperial se practicaba el confucionismo, una religión ligada a los elementos del gobierno secular y al orden social existente, no solo con su organización, sino con rituales y teología, lo que la diferenciaba del cristianismo, entendido como una religión institucionalizada e independiente de los gobernantes (Standaert, 2010: 275).

Pese a las dificultades iniciales, la Compañía de Jesús logró introducirse en China, principalmente por obra de los padres Miguel Ruggieri, y Matteo Ricci, asentando su labor misionera, por medio de la inculturación, es decir, adaptando el cristianismo al pueblo chino, para lo cual empleó tres ejes de acción: ofrecer servicios científicos como método de acceso a la Corte Imperial; explicar el cristianismo en el lenguaje chino; y "aceptar" las tradiciones de esta cultura asiática (Marino, 2017: 397).

Hacia el año 1590, Matteo Ricci había aprendido el idioma chino con soltura, permitiéndole traducir al latín "Los Cuatro Libros de Confucio", creando el primer sistema de transcripción al alfabeto latino de la lengua china, y alcanzando un notable mimetismo con aquella sociedad, al desechar sus hábitos de monje, en favor de la vestimenta de los letrados (por ser estos superiores en la escala social), unido al crecimiento de su pelo y barba, razones por las que se consideran a Matteo Ricci el "padre de la sinología occidental" (Sequeiros San Román, 2009: 288).

Asimismo, el padre Ricci ofreció diferentes presentes, como pinturas y un reloj europeo, que junto a sus traducciones hicieron que fuese apreciado en la Corte Imperial, consiguiendo la conversión de notables de la época (Standaert, 2010: 272). Matteo Ricci falleció en 1610, dejando a su marcha 2.500 cristianos 
autóctonos, permitiéndose tras su muerte el establecimiento de una misión permanente en el país (Sotomayor Muro, 1991: 229). Con permiso del Emperador su sepelio tuvo lugar en Pekín, en el exterior de la puerta este de la ciudad; posteriormente, su sepultura sería destruida en dos ocasiones: en 1900 durante la Rebelión de los Boxers, y en 1966 a causa de la Revolución Cultural (Sequeiros San Román, 2009: 295).

En conjunto la obra de Matteo Ricci no llegó a culminarse, como consecuencia de la incomprensión del método de inculturación empleado por sus compañeros jesuitas, y por la llegada a China de otras órdenes a partir de 1631, contrarias todas ellas a estas prácticas, ignorantes de la universalidad demostrada por el cristianismo en su constante acomodación a las sociedades helenísticas o sirias, sin que llegase a materializarse en el mundo chino, concluyendo cualquier esperanza de continuidad para sus comunidades, con la condena final de estos cultos desde el lado católico, por Benedicto XIV en 1742 (Sotomayor Muro, 1991: 230), prohibiendo a los misioneros plantear nuevas cuestiones al respecto, e imponiendo un juramento de obediencia (García-Villoslada, 1940: 491).

Además, las divergencias entre la Iglesia Católica respecto del uso de los ritos chinos, había causado que el Emperador Kangxi decretase la prohibición de las misiones en 1717 (Fuk-Tsang, 2011: 150), y de la religión en 1724, ordenando el arresto y expulsión de los misioneros, y el encarcelamiento y decapitación de los cristianos (García-Villoslada, 1940: 495).

\section{EL DESARROLLO DEL CRISTIANISMO DURANTE LA ETAPA DEL IMPERIALISMO OCCIDENTAL (1842-1945)}

El sucesor de Kangxi, Kien-Long, continuó endureciendo la persecución de los cristianos al dar muerte a los misioneros entre 1746 y 1748 (García-Villoslada, 1940: 491), no restableciéndose una situación de armonía hasta los Tratados firmados con Estados Unidos y Francia en 1844, que permitieron una mayor libertad religiosa, concediendo a los misioneros vivir libremente en cualquiera de los puertos abiertos 
al comercio con el exterior, y a los cristianos chinos practicar su fe donde sea que viviesen (Sweeten, 2020: 5-6).

Durante el periodo de prohibición del cristianismo en China, hubo algún intento de evangelización desde la rama protestante. El protestantismo es un término ambiguo empleado para designar la aparición en Europa en el siglo XVI, de nuevos grupos de creyentes escindidos de la Iglesia Católica, entre los que se encuentran luteranos, presbiteranos, anglicanos, anabaptistas, menonitas (así como sus variantes posteriores), que comparten como señas de identidad común: la creencia en la autoridad de la Biblia como fuente de doctrina y práctica de vida religiosa; el rechazo a la autoridad del Papa; la salvación por la gracia de Jesucristo a través de la fe en él; el sacerdocio de todos los creyentes; la no creencia en la transmutación durante la eucaristía; y la negación del purgatorio (Melton, 2005: xi).

El primer intento de arraigo protestante en China fue en 1807, por el misionero Robert Morrison de la Sociedad Misionera de Londres, quien se dirigió a la colonia portuguesa de Macao, siendo expulsado por sus autoridades, encaminándose posteriormente a Cantón (Kim-kwong, 2019: 14), y finalmente en 1809 a Guangzhou, donde obtuvo un puesto remunerado de traductor para la Compañía Británica de las Indias Orientales, lo que le permitió realizar su labor evangelizadora (Clarke, 2013: 55). Por el contrario, en aquella época, la mayoría de cristianos eran católicos, estimándose que en los años previos a la Primera Guerra del Opio, había más de 200.000 católicos en el país (Reilly, 2004: 47).

La Primera Guerra del Opio, iniciada en 1839, se debió a la insatisfacción recíproca de los comerciantes británicos en Guangzhou (ante los términos comerciales de China), y a la creciente preocupación de los funcionarios imperiales por el impacto ocasionado por las importaciones británicas de opio (Harrison, 2013: 67). Esta sustancia había sido prohibida desde 1729 (época en que se contrabandeaba una media de 1.500 kilográmos anuales), y era castigada su tenencia con la pena de muerte desde 1820 (cuando la cifra en su contrabando 
alcanzaba las 750 toneladas anuales, habiendo su número ascendido en el año de la guerra a las 2.000 toneladas) (Escohotado, 1994: 71).

El Tratado de Nanking, firmado el 29 de agosto de 1842, puso fin a la Primera Guerra del Opio, comenzando así la época de los Tratados desiguales (bupindeng tiaoyue) y el siglo de la humillación china (guochi), que marcaría en lo sucesivo el sentido nacionalista del país (Wang, 2008: 1). Dicho tratado impuso la obligación de otorgar indemnizaciones a los británicos, y la cesión a estos de la ciudad de Hong Kong, aprobándose la apertura de cinco puertos comerciales chinos (Fuzhou, Guangzhou, Ningbo, Shanghai, y Xiamen), que permitirían la entrada furtiva de misioneros cristianos (Clarke, 2013: 51), y el retorno de los jesuitas en 1842, por impetración de los cristianos de la región (García-Villoslada, 1940: 684).

Con el propósito de igualar la posición británica, los estadounidenses procedieron a firmar el Tratado de Wanghia, el 18 de mayo de 1844, que facultó la apertura de los puertos chinos a los Estados Unidos de América, estableciendo la libertad de acción para sus ciudadanos en torno a la cuestión religiosa, tal y como estipulaba en su artículo XVII:

Los ciudadanos de los Estados Unidos que residan o se encuentren en cualquiera de los puertos abiertos al comercio exterior, gozarán de todas las comodidades necesarias para obtener casas y lugares de negocios, o para contratar sitios de los habitantes para construir casas y lugares de negocios, y también hospitales, iglesias y cementerios (USC US-China Institute, 2021).

Esta capacidad aperturista incentivó a protestantes y metodistas estadounidenses a viajar a China, principalmente a Hong Kong, a predicar el evangelio, con la Misión Bautista Americana, y la Convención Bautista Sureña (Coulson, 1996: 10). Por otra parte, los franceses firmaron el 24 de octubre de 1844 el Tratado de Whampoa, en el que al igual que el de los estadounidenses, se reconocía en su artículo XXII, la libertad de culto a sus nacionales que se encontrasen en los puertos chinos abiertos al comercio exterior (Reilly, 2004: 49). 
Es de destacar que el Tratado de Whampoa se efectuó gracias a las negociaciones del embajador francés, el barón de Lagrené, quien consideró que debía enfatizarse el reconocimiento de la libertad de culto, para favorecer los intereses católicos franceses en la región (Mau, 2021). Ello permitió una mejora en el financiamiento de las misiones católicas en esta nación, creándose a propósito dos grupos franceses destinados a la evangelización, l'Oeuvre de la Propagation de la Foi (La Obra de Propagación de la Fe), y l'Oeuvre de la Sainte Enfance (La Obra de la Santa Infancia), llegadas a China en 1845 y 1846 respectivamente (Harrison, 2013: 68), lo que garantizó el predominio de los misioneros franceses en el país hasta comienzos del siglo $X X$, teniendo en cuenta que en 1914, de los 1.500 misioneros extranjeros que había predicando en China, 850 eran franceses (Clarke, 2013: 57).

En 1856 se produjeron dos hechos que afectaron nuevamente las relaciones con occidente y ocasionaron la Segunda Guerra del Opio: el abordaje del barco Arrow, de pabellón británico, acusado de piratería por las autoridades chinas, y el asesinato del clérigo francés Abbé Auguste Chapdelaine, que forzó a la revisión de los tratados existentes (Wang, 2008: 16-17), y a la redacción y aprobación del Tratado de Tianjín, de 1858, negociado por el barón de Gros, que incluyó en su artículo 13 la protección expresa a los cristianos para profesar su fe, y a los misioneros su desplazamiento libre por China (Charbonnier, 2007: 321). Así lo disponía el artículo VIII de la versión británica del Tratado, delegando en las autoridades chinas la obligación de proteger a los creyentes:

La religión cristiana, tal como la profesan los protestantes o los católicos romanos, inculca la práctica de la virtud y enseña al hombre a hacer lo que debe. Las personas que la enseñen o la profesen, por lo tanto, tendrán derecho a la protección de las autoridades chinas, y ninguna de ellas, que ejerza pacíficamente su vocación y no ofenda las leyes, será perseguida o perturbada (Gregory, 2002: 92).

El asesinato de Abbé Auguste Chapdelaine fue uno de los conocidos como jiao an (traducido como "casos de misioneros"), referente a los incidentes ocurridos entre 1861 y 1911, cuya cifra rondaría de 600 a 2.000 casos (Young, 2013: 44), 
unido a unas 200 revueltas (Stockwell, 2003: 99). En este contexto se desarrolló entre 1851 y 1864 un periodo de desestabilización social, la rebelión Taiping, que ocasionó aproximadamente la muerte de 20 millones de personas (Reilly, 2004: 3). Causada por diferentes factores, destaca la aparición del lider mesiánico Hong Xiuquan, quien a través de sus discursos inspirados en el cristianismo (ya que en 1846 había recibido educación por el misionero bautista Issacher Roberts), consiguió armar un movimiento que capturó Nanjing en 1853 (renombrada como Tianjing por sus conquistadores, significando capital celestial), y que amenazó con tomar Beijing en 1854 (Gregory, 2002: 104-105).

Otro periodo de desestabilización social fue la Rebelión de los Boxers (18991901). Como detonante de esta rebelión, suele identificarse la conquista por los alemanes en noviembre de 1897 de la bahía de Kiaochow, y el fracaso de las reformas iniciadas por el gobierno en 1898 (Tiedemann, 2010: 338). En esas circunstancias, el 15 de marzo de 1899, el Imperio otorgó a los obispos y misioneros católicos un estatus oficial en los tratos con las autoridades chinas (Young, 2013: 67).

Los Boxers comenzaron como grupos de artes marciales que se reunían en los templos de la provincia de Shandong, hasta que su crecimiento les permitió en 1900 convertirse en milicias respaldadas por el gobierno central, con el objetivo de expulsar a las naciones extranjeras, los misioneros y los cristianos chinos (Harrison, 2013: 92-93). En conjunto, los boxers asesinaron a 5 obispos, 31 sacerdotes europeos, 9 monjas, y más de 30.000 chinos católicos (Kejia, 2005: 70-71), en un tiempo en el que el país albergaba unos 100.000 protestantes y 700.000 católicos (Young, 2013: 46), grupo este último, que en tres décadas había duplicado el número de creyentes, desde los 369.411 registrados en 1870 (Kejia, 2005: 56).

En 1911 se originó una ruptura en la historia de China, con la revolución de Xinhai, que supuso el fin de la monarquía, calificada por Franke \& Trauzettel (1982) como "un proceso inconcluso" que "encubrió los conflictos internos y sociales", y 
"preparó definitivamente el terreno para la verdadera revolución" (329), y la proclamación de la República de China.

En esa misma década, el Papa Benedicto XV publicó la encíclica Maximum Illud en noviembre de 1919, que abogó por la indigenización de las iglesias establecidas fuera del continente europeo (Yik-Yi Chu, 2016: 5), en unos años en el que de 140 obispos que había en China, 114 eran extranjeros (Kim-kwong, 2019: 12). A fin de cambiar la situación, en 1926 publicó la encíclica Rerum Ecclesiae que permitió la creación de un episcopado nativo (Tiedemann, 2010: 519).

La acogida positiva del catolicismo en China, se comprueba con el crecimiento de los católicos en el país, de 1.364 .618 creyentes en 1910, a 1.971.189 en 1920, y 3.183.000 en 1940 (Kejia, 2005: 73), que estuvo motivada por la labor misionera realizada, sirviéndo de ejemplo el hecho de que en el año 1936 la mitad de extranjeros en China eran misioneros (unas 6.020 personas, de las cuales más de 3.600 eran católicas) (Stockwell, 2003: 100-101).

Hubo en aquellos años algún intento partidista de aprovecharse de la religión para beneficio del gobierno chino. Así fue lo ocurrido con el militar Chiang Kai-shek, líder del Kuomintang (Partido Nacionalista Chino), quien entre 1928 y 1934 organizó campañas destinadas a exterminar al Partido Comunista Chino (PCCh), liderado por Mao Zedong, generando el sustento teórico necesario para su labor, a través del movimiento "Vida Nueva", aprobado oficialmente el 19 de febrero de 1934 (Charbonnier, 2007: 405-406), imbuido en ideología fascista, apoyado de elementos cristianos y confucianos, como estructura con que combatir a los marxistas del país (Bianco, 1987: 71).

Otro evento internacional perturbó nuevamente la paz del pueblo chino, la invasión japonesa (1937-1945), un paréntesis en la confrontación entre el Kuomintang y las fuerzas comunistas del país, que hicieron un frente común contra el enemigo extranjero. 
Durante esta etapa, fueron habituales las acusaciones por el PCCh de colaboracionismo de los católicos hacia los japoneses (Charbonnier, 2007: 414). Lo cierto fue que bajo el mandato del Papa Pio XII, debe destacarse el papel desempeñado por la primera misión diplomática japonesa ante la Santa Sede, formada por el protestante Harada Ken (1892- 1973), y el católico Kanayama Masahide (1909-1997), cuyo objetivo fue garantizar el bienestar continuo de los sacerdotes católicos en los territorios ocupados por Japón, permitiendo al Vaticano transferir dinero a los sacerdotes católicos en China, además de ayudar a persuadir al ejército japonés de la necesidad de proteger a los sacerdotes de países en guerra con Japón, como Estados Unidos y Gran Bretaña (Ikehara, 2011: 98).

Por otra parte, debe indicarse que en 1944, de 6.000 sacerdotes católicos que había en el país, 500 eran alemanes e italianos, a pesar de lo cual el Kuomintang ignoró su pertenencia a potencias enemigas y les permitió seguir ejerciendo su labor (Stockwell, 2003: 522).

\section{EL CRISTIANISMO DESDE LA FUNDACIÓN DE REPÚBLICA POPULAR CHINA (1949-2021)}

El 1 de octubre de 1949 Mao Zedong proclamó la fundación de la República Popular China. Este hecho provocó un desplazamiento poblacional de 1 millón de personas a Taiwán, en un periodo en que la isla tenía 15 sacerdotes, 12.944 católicos, y que en 1969, veinte años después, había incrementado el número de creyentes a más de 300.000 personas (Chuang-sheng Chang, 2018: 27-29).

Algún autor ha indicado que los primeros conversos chinos de la época de los tratados desiguales, procedían de los estratos más desfavorecidos: pobres que trataban de recibir algo de ayuda para su sustento (razón por la que se les conocía como cristianos del arroz), o criminales que huían a las misiones para evadir a la justicia, por ser terrenos que de acuerdo a los tratados firmados con las potencias occidentales, quedaban fuera del alcance de las fuerzas del orden chinas (Stockwell, 2003: 98). 
Para 1949, un siglo después, las cifras de personas convertidas al cristianismo no pueden explicarse exclusivamente por aquellos necesitados de alimentos, o de refugio por los crímenes cometidos. Al momento de la fundación de República Popular China, el país contaba con 1.000 .000 de protestantes y 3.000.000 de católicos, aunque la toma del poder por el Partido Comunista, supuso el fin de los misioneros por ser vistos como agentes al servicio del imperialismo (Fuk-Tsang, 2011: 151-152).

En 1950 los principales grupos protestantes, la Iglesia de Cristo en China (con 177.000 integrantes), Metodistas (147.000), la Verdadera Iglesia de Cristo (125.000), y otras denominaciones menores (que en conjunto sumaban unos 30.000 fieles) (Charbonnier, 2007: 430), firmaron una declaración titulada "Esfuerzos a realizar por los cristianos chinos, para la construcción de una nueva China”, en la que establecieron para sus comunidades una política de autosuficiencia, autogestión, y autopropagación (Stockwell, 2003: 103), surgiendo así el Movimiento Patriótico Chino Protestante de las Tres Autonomías (Stockwell, 2003: 800); esquema idéntico al adoptado por los católicos, quienes fundaron en 1951, la Asociación Patriótica de Católicos Chinos, independiente de Roma (Stockwell, 2003: 103).

El Papa Pio XIl emitió en 1954 la encíclica Ad Sinarum Gentes, dirigida explícitamente a la población china, en la que rechazaba los movimientos surgidos al amparo del nuevo gobierno comunista:

Los promotores de tales movimientos con la mayor astucia buscan engañar y desviar del camino correcto. Para ello afirman falsamente que los únicos verdaderos patriotas son los que se adhieren a la Iglesia ideada por ellos, es decir, a la que tiene las "Tres Autonomías". Pero en realidad buscan establecer una iglesia "nacional", que ya no podría ser católica porque niega su universalidad o más bien la "catolicidad" de la sociedad verdaderamente fundada por Jesucristo, que está por encima de todas las naciones y las abraza a todas y cada una (Pio XII, 1954).

Attribution-NonCommercial 4.0 International (CC BY-NC 4.0).

e-ISSN: 2660-552X 
Ese mismo año se aprobó el 20 de septiembre la primera Constitución de República Popular China, cuyo artículo 88 reconoció el derecho a la libertad de creencia siempre que no incurriese en actividades contrarrevolucionarias (Charbonnier, 2007: 426). A pesar de representar el 0,6\% de la población total, al ser los católicos un grupo estructurado y con capacidad de organizar acciones coordinadas a escala nacional, les hizo ser percibidos como enemigos por el gobierno (Stockwell, 2003: 849), razón que provocó el encarcelamiento en 1956 del principal líder, el obispo de Shanghai, Gong Pinmei, liberado en 1986 (Madsen, 2004: 94), o del jesuita Dominic Tang Yiming, quien estuvo preso entre 1958 y 1980 (Criveller, 2020: 11), causando desde entonces la existencia clandestina de los católicos dependientes de Roma, guiados por el sensus fidelium, frente a la nueva denominación dependiente del gobierno (Charbonnier J. , 1993: 55).

El nuevo régimen calificó el cristianismo de acientífico y supersticioso, contrario a las doctrinas progresistas, materialistas y científicas del marxismo y el comunismo, lo que llevó a la represión de las iglesias cristianas, con la abolición de las denominaciones protestantes en 1958, y la detención de todos los cultos desde 1966 (Ming Ng, 2015: 155), cuando Mao declaró la religión como un vestigio de la antigua sociedad que pretendía suprimir (Fuk-Tsang, 2011: 151), en el contexto de inicio de la Revolución Cultural (1966-1976). Con el fallecimiento de Mao y el fin de la Revolución Cultural en 1976, en 1979 se permitió nuevamente la reapertura de los templos (Ming Ng, 2015: 155).

El 31 de marzo de 1982, se aprobó la Directiva titulada "El punto de vista básico y la política sobre la cuestión religiosa durante el periodo socialista de nuestro país", conocida como Documento 19, por el que se rechazó el ejercicio de cualquier acción coercitiva contra los creyentes, al entender que la religión seguiría existiendo aun estando un régimen socialista (Bays, 2011), y cómo la represión maoísta sólo logró volver las comunidades aún más subterráneas (Madsen, 2004: 96). Ello supuso un renacimiento de los cristianos que habían sobrevivido a los años de hostilidad revolucionaria, manteniendo el culto pese a la adversidad, a las que se 
unieron nuevos conversos, principalmente antiguos guardias rojos desilusionados de la política (Stockwell, 2003: 813).

La política religiosa del gobierno se vio reforzada el 7 de noviembre de 1993, cuando el presidente Jiang Zemin pronunció su discurso en el Congreso de Trabajo del Frente Nacional, aprobando sus "Tres Sentencias para realizar bien el trabajo religioso": la aplicación persistente por el PCCh de dicha política de forma correcta y completa; el fortalecimiento del control de los asuntos religiosos de acuerdo con la ley; y fomentar la adaptación mutua de religión y sociedad socialista (Ming $\mathrm{Ng}$, 2015: 156).

Igualmente, con carácter interno bajo el mandato de Jiang Zemin, las condiciones que se estipularon para retomar las relaciones diplomáticas con el Vaticano, eran que la Santa Sede renunciase a interferir en cualquier asunto interno de China, y se negase a mantener contacto con Taiwán (Criveller, 2020: 13). Debe indicarse que desde 1951 no ha existido relación formal entre ambos países, habiendo sido el único acercamiento diplomático el efectuado para el Acuerdo provisional entre la Santa Sede y la República Popular China, sobre el nombramiento de obispos, firmado en Beijing el 22 de septiembre de 2018, por el cual se reconoce por las autoridades asiáticas la nominación de cargos eclesiásticos desde Roma, que se mantendrá en vigor hasta el 22 de octubre de 2022 (Vatican news, 2020).

Debe aclararse que la omisión en el presente estudio de la Iglesia Ortodoxa Rusa, se debe a la escasa difusión que ha tenido en el país. La presencia en China de esta religión se remonta a 1685, tras la captura de algunas tropas zaristas (entre las que se encontraba el sacerdote Maksim Leontbev, quien portaba una imagen de San Nicolás), por el ejército imperial Qing (Kim-kwong, 2019: 13). La primera misión oficial fue enviada en 1715 (a la que sucedieron 18 misiones más hasta el inicio de la revolución de octubre en 1917), constituyéndose en 1924 la Iglesia Ortodoxa de China (bajo la jurisdicción del patriarcado de Moscú desde 1946, y declarada independiente en 1956 tras la ruptura sino-soviética), que llegó a tener a finales del 
siglo XX, alrededor de 30.000 cristianos ortodoxos, en su mayoría rusos, sin que en el presente sea una de las religiones reconocidas por las autoridades chinas (FukTsang, 2011: 159-160).

En cambio, el protestantismo chino, suele identificarse como una fuerza social capaz de rivalizar con el PCCh en la reclamación del espacio público, pese a su desventaja demográfica (Yin, 2015: 232), debiendo distinguirse entre aquellas denominaciones bajo tutela del Estado, de las que actúan independientes del mismo en la clandestinidad (Charbonnier J., 1993: 57).

La Iglesia del Movimiento Patriótico de las Tres Autonomías, es la iglesia protestante oficial de China, cuyos líderes son designados y capacitados teológica y políticamente, por la Administración Estatal de Asuntos Religiosos, un departamento dependiente del Consejo de Estado (Yin, 2015: 235). Frente a ella, se encuentran las denominadas "Iglesias caseras", por corresponder a reuniones ofrecidas en casas, cuyas características comunes son rechazar los movimientos carismáticos, y apoyarse en la literalidad de la palabra de la Biblia (Stockwell, 2003: 816-817), manteniéndose por predicadores de escasa educación teológica e independientes de cualquier estructura orgánica (Yin, 2015: 236).

Son en gran parte post-denominacionales, de orientación democrática, en que prima el interés popular en las curaciones y los milagros (Gunther Brown, 2015: 68), resaltando que en el medio urbano se busca un evangelio de prosperidad, evitando la contradicción entre la devoción requerida por la religión y la modernidad racionalizada defendida por el Estado (Yin, 2015: 241).

La Constitución china de 1982, fue enmendada por última vez en 2018, recogiendo el derecho a la libertad religiosa en su artículo 36: "Ningún órgano estatal, organización pública o individuo puede obligar a los ciudadanos a creer o no creer en ninguna religión; tampoco pueden discriminar a los ciudadanos que crean o no crean en ninguna religión" (Peking University Center for Legal Information, 2018). No obstante a su reconocimiento normativo, las autoridades solo permiten cinco religiones en el país: budismo, catolicismo, islam, protestantismo y 
taoísmo (Albert \& Maizland, 2020), sin que esto garantice su protección, mostrándose cómo entre 2014 y 2018, se confirmó la destrucción de 2.000 templos y cruces en todo el país (Majumdar, 2018).

\section{CONCLUSIONES}

En cualquier caso, el cristianismo se ha sobrepuesto a las adversidades y a múltiples persecuciones, manteniendo su crecimiento. En el año 2010, la mayoría de cristianos chinos eran protestantes (con 58.040 .000 creyentes), y católicos (con 9.000 .000 de feligreses), sumando un total, atendiendo a otras denominaciones minoritarias, de 67.070 .000 cristianos, que representaban el $5 \%$ de la población del país (Pew Research, 2011), sin embargo, esta cifra podría ser superior dado que en aquella fecha el Departamento de Estado de los Estados Unidos, consideraba que en relación a los 5.300 .000 creyentes registrados ante la Asociación Patriótica de Católicos Chinos, podría haber más de 12 millones de feligreses católicos en iglesias no declaradas (Yik-yi Chu, 2012: 107).

En 2021, los cristianos oficialmente representaban el 5,1\% de la población (Central Intelligence Agency, 2021), aunque probablemente la cifra fuese superior. Actualmente, tal vez sólo los protestantes constituyan entre 93 y 115 millones de creyentes, y los católicos de 10 a 12 millones de feligreses (Albert, 2018), estimándose que de continuar el crecimiento para el año 2030, unilateralmente los protestantes podrían alcanzar la cifra de 224 millones de personas (Yang, 2017), por lo que el aumento estimado del cristianismo en términos de población, convierta posiblemente a China en la nación cristiana más grande del mundo (Hunt, 2015: 17).

Desconociéndose cuál será el desarrollo de los acontecimientos sociales, se ha confirmado con el presente artículo el progresivo crecimiento de los cristianos en China, independientemente de las derivas de los distintos regímenes que han ocupado la jefatura de este Estado asiático (incluida la actual ideología del gobierno monolítico del Partido Comunista). En los siglos de existencia del cristianismo en la 
nación sínica, se ha incrementado constantemente el número de creyentes, a pesar de su pertenencia a una tradición cultural alejada del contexto occidental, lo que únicamente puede comprenderse por el carácter universal del mensaje cristiano.

\section{BIBLIOGRAFÍA}

Albert, E. (11 de octubre de 2018). Christianity in China. Obtenido de Council on Foreign Relations: https://www.cfr.org/backgrounder/christianity-china

Albert, E., \& Maizland, L. (25 de septiembre de 2020). Religion in China. Obtenido de Council on Foreign Relations: https://www.cfr.org/backgrounder/religion-china

Bangert, W. (1981). Historia de la Compañia de Jesús . Santander: Sal Terrae.

Bays, D. (2011). A New History of Christianity in China. Wiley-Blackwell.

Bianco, L. (1987). Asia contemporánea. Madrid: Siglo XXI.

Central Intelligence Agency. (11 de mayo de 2021). China. Obtenido de Central Intelligence Agency: https://www.cia.gov/the-worldfactbook/countries/china/\#people-and-society

Charbonnier, J. (1993). The "Underground" Church. En E. Tang, \& J.-P. Wiest, The Catholic Church in Modern China: Perspectives (págs. 52-70). Eugene, Oregon: Orbis Books.

Charbonnier, J.-P. (2007). Christians in China: A.D. 600 to 2000. París: Ignatius Press.

Chuang-sheng Chang, M. (2018). The internal development of the Taiwan Catholic Church: 1950s-1960s. En F. So, B. Leung, \& E. Mylod, The Catholic Church in Taiwan (págs. 27-56). Singapore: Palgrave MacMillan.

Clarke, J. (2013). The Virgin Mary and Catholic Identities in Chinese History. Hong Kong: Hong Kong University Press. 
Coulson, G. (1996). Christians in China and Hong Kong. New York: Friendship Press.

Criveller, G. (2020). An Overview of the Catholic Church in Post-Mao China. En C. Yik-yi Chu, \& P. Mariani, People, Communities, and the Catholic Church in China (págs. 9-28). Singapore: Palgrave MacMillan.

Escohotado, A. (1994). Las drogas, de los orígenes a la prohibición. Madrid: Alianza Editorial.

Franke, H., \& Trauzettel, R. (1982). El Imperio chino. Madrid: Siglo XXI.

Fuk-Tsang, Y. (2011). Mainland China. En P. Phan, Christianities in Asia (págs. 149-172). Oxford: Blackwell Publishing.

García-Villoslada, R. (1940). Manual de historia de la Compañía de Jesús. Madrid: Compañía Bibliográfica Española, S.A.

González Salinero, R. (2005). Las persecuciones contra los cristianos en el Imperio romano. Madrid: Signifer.

Gregory, J. (2002). The West and China since 1500. New York: Palgrave MacMillan.

Gunther Brown, C. (2015). Conservative Evangelicalism: Safeguarding Theology and Transforming Society. En S. Hunt, Handbook of Global Contemporary Christianity (págs. 49-74). Leiden: Brill.

Harrison, H. (2013). The Missionary's Curse and Other Tales from Chinese Catholic Village. Berkeley: University of California Press.

Hunt, S. (2015). Introduction. En S. J. Hunt, Handbook of Global Contemporary Christianity (págs. 1-28). Leiden: Brill.

Huntington, S. (2019). El choque de civilizaciones. Ciudad de México: Paidós. 
Ikehara, M. (2011). Kanayama Masahide: Catholicism and Mid-Twentieth-Century. En K. Doak, Xavier's Legacies: Catholicism in Modern Japanese Culture (págs. 91114). Vancouver: UBC Press.

Kejia, Y. (2005). Catholic Church in China. China Intercontinental Press.

Kim-kwong, C. (2019). Understanding World Christianity: China. Minneapolis: Fortress Press.

Kim-kwong, C. (2019). Understanding World Christianity: China. USA: Fortress Press.

Kissinger, H. (2016). Orden Mundial. México, D.F.: Penguin Random House.

Küng, H. (2013). En busca de nuestras huellas. DeBolsillo.

Le Gall, J., \& Le Glay, M. (1987). El Imperio Romano. Madrid: Pressess Universitaires de France.

Madsen, R. (2004). Catholic Conflict and Cooperation in the People's Republic of China. En J. Kindopp, \& C. Hamrin, God and Caesar in China: Policy Implications of Church-State Tensions (págs. 93-106). Washington D.C.: Brookings Institutions Press.

Majumdar, S. (11 de octubre de 2018). Recent Chinese dealings with faith groups reflect a pattern of government restrictions on religion. Obtenido de Pew Research Center: $\quad$ https://www.pewresearch.org/fact-tank/2018/10/11/recent-chinesedealings-with-faith-groups-reflect-a-pattern-of-government-restrictions-on-religion/

Marino, G. (2017). La transmisión del Renacimiento cultural europeo en China. Un itinerario por las cartas de Alessandro Valignano (1575-1606). Studia Aurea: Revista de Literatura Española y Teoría Literaria del Renacimiento y Siglo de Oro, 395-428.

Mateo Donet, M. (2016). La ejecución de los mártires cristianos en el Imperio Romano. Murcia: Centro de Estudios del Próximo Oriente y la Antigüedad Tardía. 
Mau, C.-h. (2021). L'ambassade de Lagrené. Obtenido de Bibliotèque nationale de France: https://heritage.bnf.fr/france-chine/fr/ambassade-lagrene-article

McLaughlin, R. (2010). Rome and the Distant East: trade routes to the Ancient Lands of Arabia, India and China. Auckland: Continuum.

McLaughlin, R., \& Jin Kim, H. (2021). Roman envoys and trade ambassadors in Han China. En R. McLaughlin, H. Jin Kim, \& S. Lieu, Rome and China. Abingdon: Routledge.

Melton, G. (2005). Encyclopedia of Protestantism. New York: Facts on File.

Ming Ng, P. (2015). Chinese Christianity A 'Global-Local' Perspective . En S. Hunt, Handbook of Global Contemporary Christianity (págs. 152-166). Leiden: Brill.

Montero, S., Bravo, G., \& Martínez-Pinna, J. (1991). El Imperio Romano. Madrid: Visor Libros.

Negro Pavón, D. (2003). Lo que debe Europa al cristianismo. Verbo (Madrid): Revista de formación cívica y de acción cultural, según el derecho natural y cristiano, 663-736.

Peking University Center for Legal Information. (3 de noviembre de 2018). Constitution of the People's Republic of China (2018 Amendment). Obtenido de Peking University Center for Legal Information: http://en.pkulaw.cn/display.aspx?cgid=311950\&lib=law

Pew Research. (2011). Pew forum on religion \& public life. Obtenido de Pew Research: https://www.pewresearch.org/wpcontent/uploads/sites/7/2011/12/ChristianityAppendixC.pdf

Pew Research Center. (2015). The Future of World Religions: Population Growth Projections, 2010-2050. : Pew Research Center.

Piñero, A. (2007). Los cristianismos derrotados. Madrid: Edaf. 
Pio XII. (7 de octubre de 1954). AD SINARUM GENTEM. Obtenido de Vatican: https://www.vatican.va/content/pius-xii/en/encyclicals/documents/hf_pxii_enc_07101954_ad-sinarum-gentem.html

Pirenne, H. (1993). Mahoma y Carlomagno. Madrid: Alianza Editorial.

Reilly, T. (2004). The Taiping Heavenly Kingdom. Seattle: University of Washington Press.

Sequeiros San Román, L. (2009). Matteo Ricci, un jesuita en China. Razón y fe: Revista hispanoamericana de cultura, 283-296.

Sotomayor Muro, M. (1991). El camino de la inculturación en la evangelización de los jesuitas. Proyección: Teología y mundo actual, 219-233.

Standaert, N. (2010). Matteo Ricci y la cultura china. Razón y fe: Revista hispanoamericana de cultura, 269-284.

Stockwell, F. (2003). Westerners in China: A History of Exploration and Trade, Ancient Times through the Present. Jefferson: MacFarland \& Company.

Suárez Verdeguer, F. (1983). España, Europa y el cristianismo. Scripta theologica: revista de la Facultad de Teología de la Universidad de Navarra, 875-883.

Sweeten, A. (2020). China's Old Churches. Leiden: Brill.

Tiedemann, R. (2010). Handbook of Christianity in China, Volumen2. Leiden: Brill. USC US-China Institute. (2021). Treaty Of Wangxia (Treaty Of Wang-Hsia), May 18, 1844. Obtenido de USC US-China Institute: https://china.usc.edu/treatywangxia-treaty-wang-hsia-may-18-1844

Vatican news. (22 de octubre de 2020). Holy See and China renew Provisional Agreement for 2 years. Obtenido de Vatican news: https://www.vaticannews.va/en/vatican-city/news/2020-10/holy-see-chinaprovisional-agreement-renew-appointment-bishops.html 
Verstrynge, J. (2012). Rebeldes, revolucionarios y refractarios: sistema, subsistemas, y antisistemas. Madrid: El Viejo Topo.

Wang, D. (2008). China's Unequal Treaties. Lanham: Lexington Books.

Yan, K. (2014). Evangelization in China. New York: Orbis.

Yang, F. (31 de octubre de 2017). Christianity's Growth in China and Its Contributions to Freedoms. Obtenido de Berkeley Center for religion, peace \& world affairs: https://berkleycenter.georgetown.edu/responses/christianity-s-growth-inchina-and-its-contributions-to-freedoms

Yik-yi Chu, C. (2012). The Catholic Church in China: 1978 to the Present. New York: Palgrave MacMillan.

Yik-Yi Chu, C. (2016). The Chinese Sisters of the Precious Blood and the Evolution of the Catholic Church. Siingapore: Palgrave Macmillan.

Yin, P. (2015). Chinese Protestantism and the Prospect of a Public Religion. En S. Hunt, Handbook of Global Contemporary Christianity (págs. 231-246). Leiden: Brill.

Young, E. (2013). Ecclesiastical Colony: China's Catholic Church and the French Religious Protectorate. New York: Oxford University Press. 